\title{
Historias de quienes no aparecen en la historia. Reflexiones y narrativas sobre turismo rural a partir de un proyecto de museo comunitario en Mas Blanco (Aragón, España)
}

Luis del Romero Renau

Departamento de Geografía e Instituto Interuniversitario de Desarrollo Local. Universidad de Valencia. Valencia, España.

Recibido: 28 de junio de 2021. Aceptado: 29 de agosto de 2021.

\begin{abstract}
Resumen
Tradicionalmente, las narrativas construidas en torno al patrimonio cultural material e inmaterial, en cuanto oferta turística en el ámbito rural, se han centrado en destacar la figura de personajes poderosos, normalmente hombres blancos y de clases altas, y en valorizar aquellos edificios más notables, dejando en segundo plano otros casos de patrimonio vinculados a las clases populares u obreras. Partiendo de la base de que el turismo rural es una actividad que contribuye a dinamizar y diversificar la economía de estos territorios, el trabajo pretende abordar críticamente los discursos dominantes y las narrativas que se construyen sobre la historia de la inmensa mayoría de nuestras áreas rurales, especialmente, a través de aquellas iniciativas y proyectos capitalizados desde la administración pública centralizada. Como contrapunto a este análisis crítico, se muestra un ejemplo de nueva museología comunitaria desarrollada en un área rural en crisis, la comunidad autónoma de Aragón, a través del proyecto del Museo de las Masías y la Memoria Rural en la aldea de Mas Blanco en el que, tanto desde su concepción como en el relato sobre la historia de este lugar, destacan el papel de la mujer rural y de clases populares.
\end{abstract}

PALABRAS CLAVE: TURISMO RURAL. NUEVA MUSEOLOGÍA. TERUEL. DESPOBLACIÓN. MERCANTILIZACIÓN.

The history of those who do not appear in history. Reflections and narratives on rural tourism from a community museum project in Mas Blanco (Aragon, Spain)

\footnotetext{
Abstract

Traditionally, the narratives produced around tangible and intangible cultural heritage, as tourist offer in the rural area, have focused on highlighting the figure of powerful characters - usually white men, and upper classes- and on valuing the most notable constructions, leaving behind other cases of heritage linked to popular or working
} 
classes. From the basis that rural tourism is an activity that contributes to dynamize and diversify the economy of these territories, the paper aims to critically address the dominant discourses and narratives that are built on the history of most of our rural areas, especially through those initiatives and projects capitalized from the centralized public administration. As a counterpoint to this critical analysis, an example of new community museology developed in a rural area in crisis, the autonomous community of Aragon, is shown through the project of the Museo de las Masías y la Memoria Rural in the village of Mas Blanco in which, both from its conception and in the tale about the history of this place, the role of rural women and popular classes stand out.

KEYWORDS: RURAL TOURISM. NEW MUSEOLOGY. TERUEL. DEPOPULATION MARKETIZATION.

PALAVRAS-CHAVE: TURISMO RURAL. NOVA MUSEOLOGIA. TERUEL. DESPOVOAMENTO. MERCANTILIZAÇÃO.

\section{Turismo rural y museología comunitaria}

El turismo rural, cultural, gastronómico, de naturaleza, o con mil denominaciones más, es sin duda una de las actividades que se intentan promocionar para buscar el ansiado repunte demográfico del medio rural. En esta línea, el turismo ha supuesto una rápida transformación de territorios rurales en territorios globales de ocio y turismo en muy pocos años (Del Romero, 2018). No solamente ha permitido la diversificación económica en áreas rurales en declive a través de una mayor pluriactividad (Loscertales, 1999), sino que además esta diversificación y dinamización económica se ha realizado mayoritariamente a partir de pequeñas empresas familiares (Fleischer y Felsenstein, 2000), frente a otros modelos de turismo de sol y playa o urbanos, donde la actividad turística está controlada por grandes tour operadores o cadenas hoteleras. A ello hay que añadir los efectos multiplicadores del turismo en áreas rurales con relación a otros sectores a partir del consumo del turista (Huguesa y Vukotinovica, 2017), sobre todo en el sector agrícola -ya que la gastronomía y el consumo de productos y recetas locales son en sí mismos un importante atractivo turístico y una modalidad concreta como el agroturismo-, ya es una importante modalidad de turismo en numerosas áreas rurales latinoamericanas y europeas (Román y Ciccolella, 2009).

No obstante, el turismo rural también presenta numerosas externalidades negativas que se podrían resumir en dos grandes problemas, aún a riesgo de simplificar en exceso: dependencia económica y mercantilización. Respecto al primer problema, España es un ejemplo muy ilustrativo. Prácticamente ningún área rural del archipiélago balear o canario escapa a la actividad turística. Durante la crisis del coronavirus en 2020, el archipiélago canario llegó a perder hasta un $20 \%$ de su PBI como consecuencia del cierre de las islas al turismo (EFE, 2020), a raíz de su economía completamente especializada en turismo de sol y playa.

Esto sucede porque el turismo se ha convertido en las últimas décadas en el Dorado para todo territorio con sus bases económicas agrícolas, ganaderas, mineras o industriales en crisis, esto es, la inmensa mayoría del medio rural. En el caso de la Unión Europea, desde hace décadas es la principal alternativa de desarrollo rural a la agricultura y ganadería cada vez más industrializadas y, por lo tanto, con menos necesidad de mano de obra, a través de su política de inversiones de fondos europeos en el medio rural (Programa LEADER principalmente). En el caso de territorios no tan fácilmente explotables desde el punto de 
vista turístico, como áreas de montaña sin nieve, áreas lejanas de los centros urbanos o con un patrimonio natural o cultural que no está en ninguna lista UNESCO o en una guía Lonely Planet, se buscan nuevas opciones para promocionar a toda costa la llegada de turistas, como maná frente a la crisis, al éxodo rural y la despoblación (Del Romero, 2018).

Sin embargo, tras décadas de incentivos del turismo rural a toda costa, con inversiones millonarias en la construcción de casas rurales, centros de interpretación, museos y todo tipo de infraestructuras turísticas, nos damos cuenta de que esta apuesta por el turismo rural no ha terminado de cuajar en numerosos territorios rurales, donde la actividad se ha convertido en casi un monocultivo. Se promocionó el turismo como complemento de renta en el medio rural, y se quedó como única actividad en numerosas poblaciones; dependencia económica que no ha repercutido en la crisis demográfica del medio rural. Algunos trabajos recientes llegan a conclusiones demoledoras en este sentido. Masot y Alonso (2017) apuntan en su trabajo de evaluación y balance de 25 años de políticas de turismo rural en la comunidad autónoma de Extremadura, en España, que "aquellas comarcas con mejores resultados de eficacia y eficiencia en turismo rural presentan a la vez los peores indicadores económicos y demográficos”. A mediados de $2021 \mathrm{el}$ Instituto Nacional de Estadística publicó un informe sobre las ciudades más ricas y pobres de España, con unas conclusiones demoledoras: las ciudades más pobres eran núcleos de gran especialización turística. Según los datos de renta por hogar estudiados con datos de 2018, sobre los 400 núcleos urbanos más importantes del país, el más pobre resultaba ser Torrevieja, uno de los destinos turísticos más consolidados de la Comunidad Valenciana con 19.202 euros de renta media por hogar, situación que se repite en otros núcleos turísticos como Barbate y Almuñécar en Andalucía. La causa se atribuye a los bajos salarios de los trabajadores de este sector (Plaza y Sánchez, 2021).

El segundo problema que enfrenta el turismo rural es la mercantilización del espacio y de la cultura. López y Marín (2010) la definen como un proceso mediante el cual se sustraen las relaciones sociales del lugar en términos de experiencia histórica y social (de pertenencia, identidad, cotidianidad, vida material o sentido sagrado, por ejemplo), para que un lugar y algunos de sus contenidos pasen a convertirse, primordialmente, en producto para ser incorporado como mercancía al circuito del mercado cultural. Este proceso opera a través de estrategias de patrimonialización, de marketing y de creación de narrativas y puestas en escena producidas exprofeso para los turistas (Boorstin, 1964, citado por López y Marín, 2010).

Una vez asumido que la simple construcción de casas no es garantía suficiente para atraer visitantes, al igual que la construcción de una infraestructura no garantiza por sí sola la permanencia de población en el medio rural en despoblación, o la de un polígono industrial no asegura la llegada de empresas, las políticas se orientan hacia la progresiva conversión del medio rural en un parque temático, una suerte de Walt Disney para solaz y recreo del urbanita. Algunos de los componentes de la disneylandización del campo son: la proliferación por doquier de centros de interpretación, hasta de los aspectos más esotéricos, como por ejemplo el centro de interpretación de las caras de Bélmez de la Moraleda en Jaén; la progresiva conversión de muchos pueblos en centros festivos durante el verano para conseguir atraer público o visitantes, aunque sea unos pocos días al año; la conversión de bosques, playas y montañas en recintos para la celebración de todo tipo de pruebas deportivas, desde maratón (ahora denominado running), pasando por bicicletas de montaña, quads o esquiadores que celebran "la cultura del esfuerzo" 
y, de paso, llenan el bar del pueblo, o la celebración de todo tipo de eventos gastronómicos, musicales, festivos o folclóricos para atraer turismo (Del Romero, 2018). Así, el patrimonio, la cultura y las tradiciones de un territorio se banalizan, se mercantilizan y se convierten en mero objeto de consumo (Román y Ciccolella, 2009; García, 2017:105). Citando a Santana, el antropólogo Adolfo García argumenta que la patrimonialización que se está haciendo del medio rural para el turismo se realiza desde fuera y a espaldas del campesino "sin oír ni leer su memoria” (Santana, 2003, citado por García, 2017:107).

No solo incluye este proceso de mercantilización la patrimonialización y banalización de la cultura rural, también asimila la producción de nuevos espacios y de una serie de narrativas sobre los mismos que se convierten en hegemónicas, y en las que destacan los acontecimientos históricos protagonizados por hombres blancos ligados al poder de la Iglesia o del Estado. La historia oficial apenas habla sobre el poder de las minorías, de las clases populares y del medio rural o indígena, ya que está escrita por los vencedores (Algarra, 2015:21). En este sentido, es muy común en cualquier ruta turística enseñar la historia o biografía de las élites de cualquier pueblo, olvidando las clases populares como sujeto histórico (Algarra, 2015:21). De igual manera, se podría hablar de una mirada heteropatriarcal dominante en la construcción de narrativas en torno a la oferta turística ya no solo en el mundo rural, sino en todo el turismo en general, lo cual incluye al propio arquetipo del sujeto del turismo de masas (Nash, 2018). La presencia de otras razas, clases populares, mujeres o indígenas en la "pedagogía-espectáculo" que se desarrolla en una visita turística, solo es admisible si éstas presentan un suficiente "color local" (Christin, 2018:92). Estos discursos y narrativas son, además, formulados casi siempre desde las administraciones públicas encargadas de promocionar el turismo.

De cara a estas narrativas y discursos presentes en numerosas actividades de turismo rural, que contribuyen a mercantilizar y patrimonializar lo rural, desde hace décadas existen propuestas alternativas de promoción turística, sobre todo en el campo de la museología y de los estudios sobre turismo comunitario y alternativo. La museología, como disciplina que se encarga del estudio de los museos, su historia y su filosofía subyacente, destaca el hecho de que el simple acto de recopilar y mostrar determinados artefactos u objetos de arte tiene un importante componente político, ya que la producción, distribución y consumo de conocimiento son siempre actos políticos (Vergo, 1997, Macdonald, 2010). Esta idea de la función social y política de los museos sentó las bases de la nueva museología (McCall y Gray, 2013). Frente a la museología tradicional, esta corriente desarrollada desde los años setenta defiende como nuevos principios la democracia cultural, la comunidad, el territorio, la concienciación, el sistema abierto e interactivo, el diálogo entre sujetos y la multidisciplinalidad (Maure, 1996). Si bien la nueva museología propone una mayor interrelación entre el museo, el contenido y la comunidad donde se halla (Urtizberea, 2008), algunos autores consideran estas propuestas ingenuas, puesto que cualquier comunidad no deja de ser compleja, conflictiva y desigual, lo que dificulta su adhesión a una determinada propuesta patrimonial.

Pese a esta crítica, existe un amplio consenso ya traducido en numerosos proyectos museísticos, sobre la necesidad de reforzar la relación entre los museos y la comunidad, lo que implica no solo una mayor interacción con el visitante, sino un mayor control por parte de éstos y de la comunidad sobre la organización del propio museo (McCall y Gray, 2013). Este mayor vínculo con la comunidad de un proyecto museístico en un medio rural implicaría que el propio museo se convierta en un polo de atracción turística y dinamización económica 
para un turismo rural diverso y sostenible. Pero, sobre todo, que los discursos y narrativas contenidas en él fuesen más accesibles al público en general y que éstas mostrasen la diversidad social y cultural de un territorio, con todas sus contradicciones.

Ante esta propuesta crítica, la museología clásica ha ido evolucionando, especialmente, a la hora de reforzar la interacción con el público visitante (Macdonald, 2010), aunque no tanto en su dimensión política. El museo clásico estaría controlado por grupos sociales vinculados a las élites de cada territorio, cuya función primordial sería aleccionar y disciplinar a la masa social con el fin de fijar su posición y rol en la sociedad (Bennet, 1995). La nueva museología tiene, por lo tanto, muy en cuenta el discurso de Foucault de que poder y conocimiento están estrechamente interrelacionados de forma que el poder intenta construir verdades (Foucault, [1977] 2007), y que las instituciones relacionadas con ese poder, como los museos, intentan refrendar (Macdonald, 2010). $\mathrm{Si}$ a la corriente de la nueva museología se le añade el epíteto de comunitario, se abre una nueva dimensión que habla ya no solo de que las narrativas, artefactos a exponer y hechos a destacar son construidos por una comunidad determinada, sino que además la propia concepción, gestión y mantenimiento están a cargo de la comunidad y no de una institución pública o privada, con todos los desafíos que eso conlleva.

\section{Objetivos, metodología y localización}

El objetivo de este trabajo es analizar una aplicación práctica de los preceptos de la nueva museología en un medio rural con problemas de despoblación, como es la provincia de Teruel, en la comunidad autónoma de Aragón (España). Pese a que se trata de un medio rural en crisis y con escasa población y actividad económica, los modelos de turismo no escapan al análisis de dependencia y mercantilización efectuado anteriormente. En primer lugar, tras varias décadas de políticas de desarrollo rural en esta comunidad autónoma, una de las principales conclusiones a las que se ha llegado en diferentes trabajos es que existe un paulatino aumento de la dependencia económica del territorio frente al turismo rural, en detrimento de otras actividades como la agricultura, la ganadería o la industria (Marín-Yaseli y Martínez, 2007). Este turismo ha descansado, sobre todo, en un modelo residencial de casas rurales o chalés, y en la promoción activa de todo tipo de recursos territoriales: nieve, gastronomía, rutas de patrimonio cultural, centros de interpretación o museos, que han buscado "activar" nuevos recursos turísticos a través de un espectacular aumento de la oferta.

No obstante, desde el punto de vista demográfico, este incentivo del turismo rural no ha conseguido por sí solo revertir la grave situación demográfica que la región ha sufrido durante décadas. Para algunos autores, incluso, el desarrollo turístico parece haber tenido efectos perversos sobre otras actividades, consolidando el escenario de crisis rural: "La pujanza del turismo ha llevado a un fuerte retroceso del sector primario, que se muestra incapaz para competir por la mano de obra y por los espacios más fértiles" (Laguna y Lasanta, 2002). El proceso de cambio hacia una economía basada en el turismo rural no ha sido precisamente equilibrado; junto a beneficios evidentes muestra zonas de sombra inquietantes (Laguna y Lasanta, 2002; Marín-Yaseli y Martínez, 2007). Cabe decir, sin embargo, que la idea de que una excesiva dependencia en el turismo no repercute necesariamente en el problema de la despoblación es defendida también por otros autores (Masot y Alonso, 2017; Del Romero, 2018). 
En una de las localidades más afectadas por la despoblación del sur de Aragón, como es el caso de San Agustín (Teruel), comenzó su andadura en 2014 la asociación cultural y de custodia del territorio Recartografías, cuyo objetivo principal fue dinamizar social y económicamente a este municipio, que entonces contaba con apenas 130 habitantes censados, a través de una propuesta de turismo rural basada en el modelo de nueva museología y huyendo de los procesos de patrimonialización hegemónicos. Se trata de una propuesta altamente innovadora, ya que la aplicación práctica de los preceptos de la nueva museología, sobre todo en la dimensión de fuerte vínculo entre museo y comunidad, apenas había tenido desarrollo en Aragón, salvo en el caso del parque cultural de Molinos, que constituyó la más temprana experiencia de nueva museología en España (Sánchez, 2020). Este caso se convirtió en un oasis artístico y cultural en un territorio como el de Teruel, con escasa oferta museística, muy ligada ésta a los modelos y cánones de la museología clásica.

En este marco de acción, durante siete años, el autor del presente artículo ha sido uno de los impulsores del Museo de las Masías y de la Memoria Rural de Mas Blanco, en la localidad de San Agustín. La principal metodología empleada en este trabajo ha sido, por tanto, la observación directa de todo el proceso de creación del museo desde 2014 hasta su inauguración en 2019. Una observación no solo directa, sino también participante, que ha llevado a interactuar con diferentes administraciones, vecinos y asociaciones para conseguir consolidar el proyecto de este museo como dinamizador del municipio; como una oferta turística que pretende mostrar toda la complejidad, injusticia y tradiciones de la sociedad rural masovera a través de su emplazamiento en diferentes edificaciones que fueron abandonadas hace años por sus propietarios debido al éxodo rural, y que han sido rehabilitadas para este fin.

\section{Contexto del Museo de las Masías y la Memoria Rural}

El Museo de las Masías y de la Memoria Rural se halla en una aldea denominada Mas Blanco, que depende del municipio de San Agustín. Se trata de un municipio de montaña, fronterizo con la Comunidad Valenciana y que tradicionalmente ha vivido de la ganadería ovina y de la agricultura de secano. Actualmente cuenta con 119 habitantes empadronados (IAEST, 2020), una cifra mucho menor a la de su máximo histórico de hace un siglo, cuando contaba con 1.477 habitantes. Estos datos muestran que, en un siglo, esta población ha perdido un $92 \%$ de su censo, sobre todo por las grandes oleadas migratorias hacia las grandes ciudades de la segunda mitad del siglo XX, en el caso particular de San Agustín, hacia Barcelona y su área metropolitana mayormente. A su vez, San Agustín se encuentra en la comarca de Gúdar-Javalambre, también territorio eminentemente montañoso que se encuentra con una situación demográfica similar, ya que en la actualidad cuenta con 7.363 habitantes mientras que hace un siglo (según el censo de 1920) contaba con 33.292 habitantes, una caída menor que la de San Agustín, pero que de todas formas representa un 78\% menos de población (IAEST, 2020).

Pese a que el resto de la comarca ha apostado desde hace décadas por el turismo rural como principal motor económico, con la construcción de dos importantes estaciones de esquí, varias urbanizaciones, rutas culturales, diez museos y trece oficinas de turismo (Comarca de Gúdar-Javalambre, 2020), ello no ha repercutido de manera positiva en 
Historias de quienes no aparecen en la...

la demografía -o lo hizo de manera muy moderada-. De hecho, el municipio de Valdelinares, que acoge a una de las principales estaciones de esquí de la región y es, por esta razón, uno de los principales destinos turísticos de la comarca, pese a su dependencia del turismo ha experimentado una evolución muy semejante a la de San Agustín, perdiendo un $89 \%$ de su población en el último siglo, hasta llegar a los 88 habitantes que en la actualidad se encuentran empadronados allí.
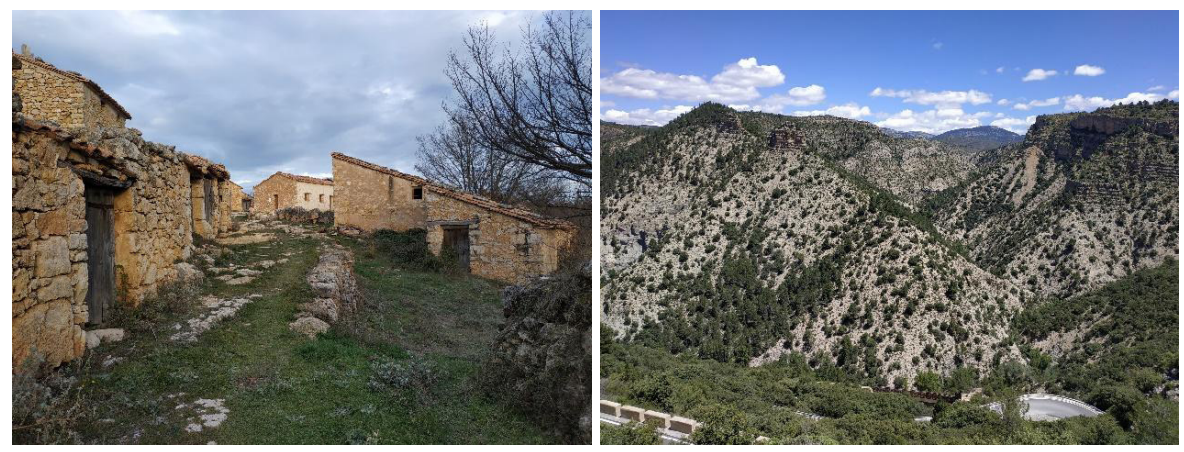

Figura 1 (izq.). Vista general del barrio de Mas Blanco. Figura 2 (dr.). Paisaje típico de montaña de la comarca de Gúdar-Javalambre: Arcos de las Salinas. Fuente: fotografías del autor.

A lo largo de la historia, Gúdar-Javalambre, al igual que el de otras muchas áreas montañosas, ha sido un territorio masovero. La masía es una explotación agropecuaria y forestal ubicada fuera de un núcleo urbano, y con frecuencia en lugares aislados, donde se desarrollan actividades de pastoreo, agricultura de secano, pequeñas parcelas de regadío y silvicultura, formando un hábitat disperso muy genuino (Casaus, 2011). La masía es habitada por una familia masovera troncal, pudiendo coincidir hasta tres generaciones bajo el mismo techo. $\mathrm{Al}$ igual que sucede en muchas otras sociedades rurales ibéricas, el modelo de familia es patrilineal y de transmisión agnaticia (por línea masculina) (García, 2017:27).

Los masoveros formaron durante siglos una sociedad con rasgos lingüísticos, culturales y sociales genuinos, completamente separada, y a veces incluso enfrentada, con la población que habitaba en los núcleos urbanos. La crisis del hábitat disperso ligada a la penetración del capitalismo, la mecanización e industrialización del campo, abocaron a una crisis irreversible en estas sociedades minifundistas adaptadas a unos territorios de montaña aislados y con pocas posibilidades de modernización si no es a partir de enormes inversiones, inasumibles en muchos casos. La crisis de la masovería fue, por lo tanto, el comienzo de la crisis generalizada de comarcas masoveras como Gúdar-Javalambre. En la actualidad, de las miles que habitaban hasta hace pocas décadas en la comarca, tan solo unas decenas continúan siéndolo, casi siempre como segunda residencia. El resto ha sido reconvertido en corrales, almacenes, o bien están en ruinas.

En el caso del municipio de San Agustín, el mundo masovero tiene la peculiaridad de que, en lugar de constituir unidades aisladas, tendieron a agruparse en pequeños barrios con dos, tres o más masías denominadas masadas. Mas Blanco es una de estas masadas; una de las más grandes del municipio con una veintena de masías. Desde el punto de vista de la situación demográfica, este término municipal llegó a tener hasta 42 masías y masadas en activo, de las cuales hoy solamente ocho están habitadas, en todos los casos menos de cinco personas (IAEST, 2020). 
La masada de Mas Blanco surgió probablemente a principios del siglo XIX, por lo que se trata de un asentamiento moderno, y llegó a alcanzar casi un centenar de habitantes a mediados del siglo XX. Para poder atender a tanta población se construyó una escuela mixta en 1950, una casa de la maestra cuatro años después y un horno comunitario hacia 1965. La cultura masovera es de base comunitaria, por lo que todos estos edificios, además de una bodega y un molino junto al río Mijares, fueron construidos y mantenidos por familias masoveras.

En 1960 Mas Blanco no disponía de luz eléctrica, agua corriente, teléfono o cualquier otro adelanto tecnológico del siglo XX. Situación que, en cierta forma, dio cuenta de su incapacidad para subsistir en un mercado agropecuario cada vez más internacionalizado y competitivo. Esto, junto con un territorio complicado desde el punto de vista orográfico y climático, fueron algunos de los factores de expulsión y éxodo masovero de Mas Blanco. A ello contribuyó de manera clara, también, la administración local, con medidas como la evacuación de masías de la zona para poder combatir la guerrilla antifascista del maquis (1947), el cierre forzoso de la escuela de Mas Blanco en 1973 que obligó a reunir a todos los niños/as de masías en una escuela-hogar, o la casi nula inversión en la mejora de caminos en las décadas siguientes. Así, a principios del siglo XXI tan solo quedaban cuatro personas viviendo en Mas Blanco, en un barrio con un importante patrimonio cultural material e inmaterial en vías de desaparición.

\section{Discusión: el museo como recurso turístico comunitario}

\section{Cronología del Museo de las Masías y de la Memoria Rural}

La asociación cultural y de custodia del territorio Recartografías surgió en 2014 en el ámbito académico de la Universitat de València, por iniciativa de una serie de personas preocupadas con el creciente problema de la despoblación en el medio rural y de la ineficacia de las políticas de desarrollo rural puestas en marcha en las últimas décadas, sobre todo a partir de la política agrícola y rural europea (PARC).

Después de un trabajo sobre los pueblos deshabitados y abandonados en la provincia de Teruel (Del Romero y Valera, 2013), Recartografías decidió adoptar una estrategia completamente distinta a la que a priori correspondería a una asociación cultural y académica. Pasó así de la acción basada en estudios, informes y producción científica, a un proyecto de rehabilitación de un núcleo deshabitado como Mas Blanco, en el municipio de San Agustín, sin ninguna actividad turística en aquellos años. El camino tradicional a seguir en un proyecto de estas características habría sido solicitar una ayuda de la Unión Europea para rehabilitar algunos de los edificios para su uso museístico, o incluso como casa rural para atraer a nuevos visitantes. Luego, encargar a una empresa especializada la concepción y montaje de una exposición permanente sobre cultura rural y recurrir a la administración pública para dotar de contenido al área expositiva. Pero en el caso de Recartografías se recurrió a una estrategia completamente innovadora para la época y muy poco empleada hasta hoy: crear un museo a través de un proyecto de custodia del territorio, en este caso, aplicado a un inmueble con valor patrimonial en manos públicas como es la antigua escuela de Mas Blanco.

Se puede definir la custodia del territorio como un mecanismo de conservación del medio territorial desde una óptica privada, que configura un sistema integrado de 
protección y que contempla la preservación del territorio asociada al desarrollo de las comunidades, a su sensibilización y educación adecuadas, y a satisfacer las necesidades globales de sostenibilidad como modelo (Gómez, 2005). No fue una institución pública o privada la que promovió el proyecto de creación de un museo dedicado al mundo masovero, sino una asociación cultural que nació en la academia, pero que pronto trazó fuertes vínculos con la población de San Agustín, pese a no tener los miembros fundadores ninguna relación familiar con en el municipio, la comarca o la región. En este sentido, los primeros años del proyecto estuvieron consagrados a realizar trabajos de restauración con técnicas de bioconstrucción y construcción artesanal para recuperar la antigua escuela que en 2014 se hallaba en riesgo de ruina total tras un abandono que había durado más de cuarenta años. La fuerza de trabajo fueron voluntarios/as miembros de la asociación, con el apoyo del ayuntamiento desde el punto de vista legal. Los trabajos de rehabilitación duraron dos años, puesto que se realizaban en días festivos y fuera del duro invierno.

Un primer punto de inflexión fue enero de 2016, cuando se reinauguró la escuela, acto al que acudieron numerosos habitantes y descendientes de Mas Blanco que en ese momento vivían en Barcelona a seis horas de Mas Blanco. La escuela fue rehabilitada tal y como era en 1950, cuando fue construida. Las emociones de revisitar un espacio relacionado con la infancia de muchos de los masoveros, en un periodo del que en general se guardan buenos recuerdos, supuso un cambio radical para Mas Blanco y para los masoveros emigrantes. La antigua comunidad dispersa en diáspora volvía a reunirse y a rememorar su infancia, la importancia y el valor de su cultura masovera, menospreciada y olvidada durante decenios por la historia oficial. Se habían sentado las bases para crear el Museo de las Masías y de la Memoria Rural siguiendo los preceptos de la nueva museología expuestos anteriormente. A partir de ese momento, la idea de Recartografías fue la de promover la creación de este museo, siguiendo tres premisas básicas: espacios no solo expositivos o con una mera función museística, sino interactivos, dando cabida a otras actividades; las narrativas y discursos sobre lo que es y fue el mundo masovero sería escrito por los propios masoveros de Mas Blanco, y en tercer lugar reivindicar el valor de lo popular y masovero como contrapunto a la oferta turística común que tiende a ensalzar y destacar, principalmente, la historia de las clases dirigentes, los nobles y la Iglesia.

Así, en 2017 se restauró y reabrió el antiguo horno comunal, no solamente como espacio expositivo, sino recuperando su antiguo uso. Ello permitió organizar una serie de eventos, que aún hoy en día perduran, de horneado comunitario y popular que sirven como ámbito de socialización y reunión en un espacio que continúa teniendo muy poca población. El horno se convirtió en un pequeño reclamo turístico en la zona, sobre todo por su restauración como tal, y no solo para el visitante ocasional o el turista convencional, pero, sobre todo, para el habitante de San Agustín. En 2018 se realizaron trabajos de consolidación, limpieza y adecuación de numerosos espacios cedidos por particulares a la asociación Recartografías, que pasarían a ser parte del futuro museo como salas de exposición. Al tiempo que la asociación avanzaba en las obras de restauración de la casa de la maestra y otros edificios, también crecía la implicación de los vecinos/as, sobre todo a través de donaciones al futuro museo y de apoyo en los trabajos de restauración. Cabe decir que durante todo este tiempo no hubo ninguna ayuda o apoyo económico institucional público o privado. 

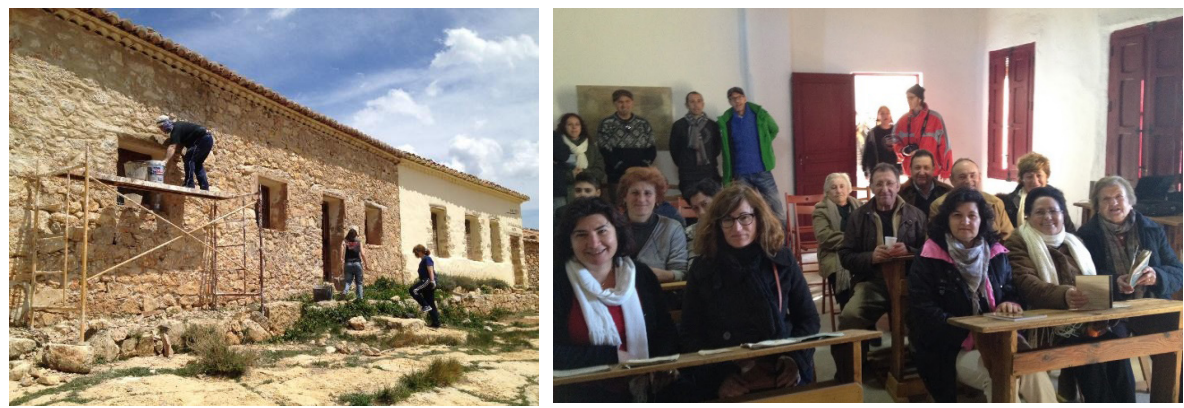

Figura 3 (izq.). Trabajos en la fachada de la casa de la maestra. Figura 4 (dr.). Antiguos masoveros en la escuela el día de su reinauguración. Fuente: fotografías cedidas por Recartografías.

Finalmente, en enero de 2019 se inauguró oficialmente el Museo de las Masías y de la Memoria Rural. La fecha escogida no fue casual, puesto que se celebraba en ese momento un siglo de historia de la Sociedad Humanitaria. Esta sociedad fue una comunidad de masoveros fundada en 1919 con el objetivo de "asistir y socorrerse mutuamente en caso de enfermedad” según reza en su acta de fundación, y que funcionó hasta los años sesenta como sociedad de apoyo mutuo vecinal no solo para el cuidado de enfermos, sino para todo tipo de asistencia familiar. A la inauguración acudieron numerosos vecinos de San Agustín y de Mas Blanco, pese a ser pleno invierno. De nuevo la visita a los edificios rehabilitados para albergar este museo, la escuela, casa de la maestra, horno y bodega, con numerosos objetos con sus nombres originales según las acepciones aragonesas (muchos de ellos de uso cotidiano en el campo o la masía), fueron una grata experiencia para los visitantes.

\section{El museo de los y las que no salen en la historia}

El museo de las masías y de la memoria rural está enclavado en el barrio de Mas Blanco. Como se ha relatado, se trata de una masada moderna, enteramente edificada siguiendo lo que se podría denominar un estilo arquitectónico rústico popular: viviendas con cubiertas a dos aguas, vanos de pequeño tamaño y fachadas exentas de cualquier elemento decorativo. En Mas Blanco no hay monumentos de interés, ni siquiera iglesia o parroquia, palacios o castillos. Es sencillamente un pequeño núcleo de masías sin un gran interés arquitectónico, pero con un museo construido, mantenido y vivido por sociedades masoveras.

Está enfocado en narrar historias de los y las que no salen en la historia, sobre todo, historias de vida de mujeres masoveras y episodios especialmente conflictivos en la historia de las masías como la guerra civil, la posguerra o los años del éxodo rural. La gestión de este museo recae en la asociación Recartografías y recibe el apoyo continuo de antiguos vecinos masoveros que contribuyen a través de su difusión o de donaciones de objetos. La política que se persigue detrás de este proyecto es convertir a Mas Blanco no solamente en un recurso turístico diferente, sino en un sitio capaz de atraer población y actividad al territorio a través de la cultura y el arte; dialogar con un entorno social cuya principal preocupación es la despoblación, tal y como se defiende desde la nueva museología. 
Hasta la fecha, una nueva familia se ha instalado de manera permanente en el barrio y otras cinco han comprado o rehabilitado viviendas, contribuyendo así a su restauración. El museo ha recibido la atención de numerosos medios de comunicación, pero ha continuado hasta la fecha siendo una muestra de que, desde la custodia del territorio, el asociacionismo y huyendo de visiones mercantilizadoras del turismo y del territorio, es posible incluso cambiar la suerte de lugares como Mas Blanco. Sin duda, el mayor éxito de esta iniciativa se sitúa en la labor de conservación y difusión de patrimonio etnológico y en la restauración de antiguos edificios masoveros, pero principalmente en la reapropiación simbólica que ha habido por parte de la propia sociedad local. Mas Blanco ha pasado de ser una población al borde de su desaparición, con solamente una pareja de neorrurales viviendo en el barrio y al que rara vez volvían los antiguos masoveros por la situación de desolación del barrio, a ser un lugar de encuentro y de socialización en el museo y, especialmente, en la escuela y el horno. Recartografías organiza regularmente visitas, talleres y seminarios para un público amplio sobre aspectos de la cultura masovera casi extinta, tanto naturales como culturales. Todo ello se ha realizado sin ninguna inversión pública, ni dentro de ninguna política oficial de desarrollo rural o turístico. De esta forma, en un contexto de crisis generalizada del medio rural aragonés, hay pequeños proyectos en lugares casi desconocidos como Mas Blanco que muestran cómo desde otras ópticas se puede intervenir en el territorio y llegar a desarrollar una actividad turística no necesariamente abocada al beneficio inmediato y al consumo masivo.

\section{Conclusiones}

El turismo rural es una de las actividades que contribuye a dinamizar y diversificar la economía de los territorios rurales. En los últimos decenios, tanto en Europa como en Latinoamérica se ha multiplicado la oferta de actividades, alojamientos y destinos en torno a temas como la cultura rural, su gastronomía, patrimonio natural o cultural. Sin embargo, el desarrollo de esta actividad no ha estado exenta de sombras. En este trabajo se han mencionado básicamente dos. Por un lado, su limitada capacidad para servir de revulsivo frente a las dinámicas demográficas regresivas de gran parte del medio rural español, sobre todo en territorios económicamente muy dependientes de este sector. Por otro, la hegemonía de un modelo de turismo que tiende a mercantilizar y banalizar lo rural para la obtención de rentas y beneficios inmediatos, que además no siempre repercuten en las comunidades rurales -en pocas ocasiones objeto de estudio y promoción más allá del discurso folclórico sobre tal o cual festividad o tradición de un determinado pueblo-.

Sin duda el museo como dispositivo de exposición y narración tiene un importante componente político, pero además forma parte del núcleo de la oferta turística de cualquier destino junto a otras actividades como el deporte, la restauración o el alojamiento; actividades donde más se ha puesto el acento en las últimas décadas. La nueva museología plantea una relación distinta entre museo y visitante y, sobre todo, pone en tensión las narrativas clásicas que se observan en la mayor parte de museos institucionales de mostrar ciertos aspectos culturales e históricos, por ejemplo, sin mencionar el papel de las clases populares en la construcción de territorio y de patrimonio.

En este sentido, el principal proyecto de la asociación cultural Recartografías, que funciona como espacio de investigación-acción, es la creación del Museo de las Masías y 
Historias de quienes no aparecen en la...

de la Memoria Rural en un antiguo lugar prácticamente abandonado, recuperando sus edificios más simbólicos desde el punto de vista social, pese a que carecen de cualquier interés arquitectónico o histórico especial. A lo largo de los años, este proyecto museístico ha contribuido a resignificar este espacio, otrora vacío y en ruinas, perteneciente a la cultura masovera, sobre la cual apenas había estudios más allá de la academia. Se convirtió así en un lugar de encuentro y de socialización, no solamente entre el turista externo al territorio y el propio lugar, sino principalmente entre los visitantes locales y antiguos masoveros que durante décadas vivieron de espaldas a su lugar de origen, por considerarlo un sitio demasiado humilde y de escaso valor como para volver o invertir en él. De este modo, el trabajo pretendió abrir un debate sobre la supuesta incapacidad más allá de la empresa privada o el Estado en un modo de producción capitalista, de llevar a cabo emprendimientos turísticos, pero sobre todo de activar procesos y acciones para abordar algunos de los desafíos de los territorios rurales como la despoblación. 


\section{Q Bibliografia}

» Algarra, D. (2015). El comú català. Barcelona: Potlach.

» Bennett, T. (1995). The Birth of the Museum: History, Theory, Politics. Londres: Routledge.

» Casaus, M.J. (2011). Bases de la sostenibilidad paisajística. Las masías en la actual comarca de Gúdar-Javalambre, del pasado rural disperso al presente recuperador. En C. Serrano (Ed.), Hábitat disperso (historia, sociedad, paisaje) (pp. 13-38). Zaragoza: CEDDAR.

» Christin, R. (2018). Manual el antiturismo. Valencia: Fuera de ruta.

» Comarca de Gúdar-Javalambre (2020). Turismo en la comarca. Recuperado de: https://turismo.gudarjavalambre.es/index.php

» Del Romero, L. y Valera, A. (2013). Territorios abandonados. Paisajes y pueblos olvidados de Teruel. Teruel: CEDDAR e IET.

» Del Romero, L. (2018). Despoblación y abandono de la España rural. El imposible vencido. Valencia: Tirant.

» $\operatorname{EFE}(2020,26$ de mayo). Cámara de Comercio prevé que el PIB en Canarias caiga un 20 \%. El Día, la Opinión de Tenerife. Recuperado de: https://www.eldia.es/ economia/2020/05/26/camara-comercio-preve-pib-canarias/1081566.html

»Fleischer, A. y Felsenstein, D. (2000). Support for rural tourism: Does it make a difference? Annals of tourism research, 27(4), 1007-1024.

»Foucault, M. (2007). Security, territory, population: lectures at the Collège de France, 1977-78. Nueva York: Plagrave McMillan

» García, A. (2017). Alabanza de aldea. Gijón: KRK.

» Gómez, J.M. (2005). Los mecanismos jurídicos de protección voluntaria del patrimonio natural. La custodia del territorio como instrumento de refuerzo de la función pública de conservación. Tesis doctoral. Universidad de Barcelona, España.

» Huguesa, K. y Vukotinovića, L.F. (2017). Economic impacts of rural tourism in rural areas of Istria (Croatia). Transformations in Business \& Economics, 16(3), 42.

» IAEST. Instituto Aragonés de Estadística (2020). Estadística local. Recuperado de: https://aplicaciones.aragon.es/mtiae/menu?idp=1\&tipo=2\&action=menu\&id $\mathrm{t}=44244$

» Laguna, M. y Lasanta, T. (2002). Desarrollo turístico y sostenibilidad en el Pirineo Aragonés: Efectos opuestos del modelo dominante. Los espacios rurales entre el hoy y el mañana. Actas del XI Coloquio de Geografía Rural. Santander, España.

» López, Á.A. y Marín, G. (2010). Turismo, capitalismo y producción de lo exótico: una perspectiva crítica para el estudio de la mercantilización del espacio y la cultura. Relaciones. Estudios de historia y sociedad, 31(123), 219-260.

» Loscertales, B. (1999). El turismo rural como forma de desarrollo sostenible. El caso de Aragón. Geographicalia, 37, 123-138. 
Historias de quienes no aparecen en la...

" Macdonald, S. (Ed.). (2010). The politics of display: Museums, science, culture. Londres: Routledge.

" Marín-Yaseli, M.L. y Martínez, T.L. (2007). Balance de las políticas públicas en el desarrollo rural del Pirineo Aragonés. Boletín de la Asociación de Geógrafos Españoles, 43.

" Masot, A.N. y Alonso, G.C. (2017). 25 Años de políticas europeas en Extremadura: turismo rural y método LEADER. Cuadernos de Turismo, 39, 389-416.

» Maure, M. (1996). La nouvelle muséologie, qu'est-ce que c'est? En M.R. Schärer (Ed.), Symposium Museum and Community II (pp.127-132). ICOFOM Study Series, 25.

" McCall, V. y Gray, C. (2013). Museums and the "new museology": theory, practice and organisational change. Museum Management and Curatorship, 29(1), 19-35.

"Nash, M. (2018). Masculinidades vacacionales y veraniegas: el Rodríguez y el donjuán en el turismo de masas. Rúbrica contemporánea, 7(13), 23-39.

"Plaza, A. y Sánchez, R. (2021). El mapa de las ciudades más ricas y pobres de España (y su relación con los hijos que tiene cada mujer). Eldiario.es. Recuperado de: https://www.eldiario.es/economia/mapa-ciudades-ricas-pobres-espanarelacion-hijos-mujer_1_7973847.html

"Román, F. y Ciccolella, M. (2009). Turismo rural en la Argentina. Concepto, situación y perspectivas. Buenos Aires: Instituto Interamericano de Cooperación para la Agricultura (IICA).

"Sánchez. S. (2020). El Mât de Molinos, peirón de la Nueva Museología. AACADigital: Revista de la Asociación Aragonesa de Críticos de Arte, 50, 2.

»Urtizberea, I.A. (2008). La Nueva Museología, el patrimonio cultural y la participación ciudadana a debate. En I.A. Urtizberea (Ed.), Participación ciudadana, patrimonio cultural y museos: entre la teoría y la praxis (pp. 11-24). País Vasco: Servicio Editorial de la Universidad del País Vasco.

»Vergo, P. (Ed.). (1997). New museology. Londres: Reaktion books.

\section{Luis del Romero Renau / luis.romero@uv.es}

Luis del Romero Renau (Valencia, 1980) es Doctor en Geografía por la Universidad Autónoma de Barcelona. Como investigador está especializado en el estudio de conflictos socioambientales y en el problema de la despoblación del medio rural en España. Además, es fundador de la asociación de investigación-acción Recartografías que trabaja en la dinamización cultural y económica del medio rural de Aragón (España). 